Article

\title{
Diversity, Vertical Stratification and Co-Occurrence Patterns of the Mycetophilid Community among Eastern Hemlock, Tsuga canadensis (L.) Carrière, in the Southern Appalachians
}

Carla Coots ${ }^{1, *}$, Paris Lambdin ${ }^{1}$, Jerome Grant ${ }^{1}$ and Rusty Rhea ${ }^{2}$

1 Department of Entomology and Plant Pathology, The University of Tennessee, Knoxville, TN 37996, USA; E-Mails: plambdin@utk.edu (P.L.); jgrant@utk.edu (J.G.)

2 USDA Forest Service, Forest Health Protection, 200 Weaver Boulevard, Asheville, NC 28804, USA; E-Mail: rrhea@fs.fed.us

* Author to whom correspondence should be addressed; E-Mail: cdillin1@utk.edu; Tel.:+1-865-974-4979; Fax: +1-865-974-4744.

Received: 27 August 2012; in revised form: 22 September 2012 / Accepted: 26 September 2012 / Published: 24 October 2012

\begin{abstract}
Over 400 species of insects have been found in association with eastern hemlock in the southern Appalachians. Eastern hemlock stands provide an ideal habitat for all life stages of mycetophilids. However, the diversity, distribution and co-occurrence patterns of these species throughout the tree canopy are unknown. This study was initiated to evaluate abundance, species richness and species composition within three designated strata in the canopy of eastern hemlock, assess species for vertical stratification patterns, and determine if co-occurrence patterns of mycetophilid species are random or non-random. During this study, 24 species representing 14 genera were identified and evaluated. Mycetophilid abundance, species richness and composition differed among the lower, middle, and upper strata. Unique assemblages were identified in each stratum, indicating vertical stratification. The upper stratum of the canopy had four exclusive species, the middle had six exclusive species, and the lower stratum had nine exclusive species. The co-occurrence pattern of mycetophilid species in the canopy of eastern hemlock was non-random.
\end{abstract}

Keywords: Mycetophilidae; eastern hemlock; canopy arthropods; co-occurrence; vertical distribution 


\section{Introduction}

Mycetophilidae is a diverse family of species belonging to the order Diptera. Most species within this family are commonly known as fungus-gnats with over 3000 species described worldwide [1] of which over 700 have been described in North America [2]. Species within Mycetophilidae are most often found throughout forests worldwide. Adult fungus-gnats are characterized by a slender body, similar to mosquitoes, with elongated coxae and tibia inclusive of long robust apical spurs. Commonly found in humid areas such as moist woodlands [1], adults exhibit congregation behaviors during the day in dark habitats especially near overhanging stream banks and tree cavities [1]. These are prominent habitat features found in stands of eastern hemlock, Tsuga canadensis (L.) Carrière. Larvae live in fleshy fungi, woody fungi, dead wood, under bark, or in nests of birds or squirrels. Most larvae are considered mycetophagous [1]. Pupation generally takes place underneath the soil line, but some species pupate in the host fungus. Mycetophilids have been shown to constitute a large proportion of the abundance and species richness in forest canopies [3]; however, the diversity of mycetophilids found among eastern hemlock is unknown.

Eastern hemlocks and associated fungal communities provide a complex of habitats that are conducive to all life stages of mycetophilids. Eastern hemlocks are shade tolerant which contributes to high survivorship in the understory with as little as $5 \%$ of full sunlight [4]. The resulting deep dense canopy produces a complex habitat with gradients in light, temperature, moisture and foliage quality [5-7], thus, resulting in a unique community of over 400 species of insects found in association with eastern hemlock in the southern Appalachians (i.e., regions within AL, GA, MS, NC, SC, and TN, USA) [8-12]. These canopies form cool, moist microclimates contrasted to that present in hardwood stands of similar age within the same area [5,13-21]. Biotic conditions such as tree architecture (needles, cones, branches, new growth, surface trunk area, and surface branch area) also have an influence on resource availability [22] and may impact how species forage, inhabit, and are distributed throughout the canopy of eastern hemlock.

In eastern hemlocks, vertical stratification has been documented to occur with Psocoptera species [11] and has been examined in spider populations in the southern Appalachians [23]. From visual observation of each stratum in eastern hemlocks, it appears that more mosses, vascular epiphytes, fleshy fungi and woody debris are located in the lower stratum, while more woody fungi and lichens appear to be located in the upper stratum, indicating a habitat and resource heterogeneity within different strata. The abundance, diversity, distribution, and co-occurrence patterns of mycetophilid species within the canopy of eastern hemlock are unknown. The main objective of this study was to evaluate abundance, species richness, and species composition within three designated strata in the canopy of eastern hemlock, assess species for vertical stratification patterns, and determine if co-occurrence patterns of mycetophilid species are random or non-random.

\section{Materials and Methods}

\subsection{Study Sites and Experimental Design}

Eastern hemlocks $(n=6)$ were selected on 5 November 2005 at Indian Boundary within the Cherokee National Forest located in Monroe County in southeastern Tennessee $\left(35^{\circ} 23^{\prime} 787^{\prime \prime} \mathrm{N}\right.$, 
8406'662" W, elevation: $543 \mathrm{~m}$ ). This study was arranged in a complete randomized one factor (stratum) design with repeated measures within each stratum. Trees were established at each of the following locations: $35^{\circ} 23^{\prime} 787^{\prime \prime} \mathrm{N}, 84^{\circ} 06^{\prime} 662^{\prime \prime} \mathrm{W}$, elevation: $543 \mathrm{~m}$; 35² $23^{\prime} 764^{\prime \prime} \mathrm{N}, 8^{\circ} 06^{\prime} 732^{\prime \prime} \mathrm{W}$, elevation: $555 \mathrm{~m}$; and $35^{\circ} 04^{\prime} 173^{\prime \prime} \mathrm{N}, 8^{\circ} 06^{\prime} 268^{\prime \prime} \mathrm{W}$, elevation: $565 \mathrm{~m}$. Tree characteristics (height, transparency, density, crown class, diameter breast height ( $\mathrm{dbh}$ ), crown condition, and percent of the tree infested with hemlock woolly adelgid (based on number of branches infested)) were documented on 25-26 November 2005. Trees $(n=50)$ were selected based on how closely documented tree characteristics matched to control for tree characteristic variables that may influence the data. Of the 50 trees, six were randomly selected for this study. Tree heights ranged from 14 to $18 \mathrm{~m}$. All trees were located in a shortleaf pine-oak (type 76) forest [24], considered co-dominant tree species at this location, and categorized as being in good condition.

\subsection{Sampling}

To examine spatial differences in abundance and species composition, each tree was divided into three strata: lower, middle, and upper, with each stratum representing $c a .1 / 3$ of the total tree height. Because of the diversity of feeding habits and mobility among species of mycetophilids, four sampling methods were used throughout each stratum to capture a wide range of mycetophilid species on each tree in August 2006, September 2007, and June 2008, using an articulating boom (Genie Z 45/22, Tigard, OR, USA). Specimens were collected using direct sampling methods (beat sheet, branch clipping, handpicking, and trunk vacuuming. Each sampling method was standardized in sampling time or area in each stratum to standardize the amount of habitat sampled. Beat-sheet samples (four $1 \mathrm{~m}$ branches with $2 \mathrm{~cm}$ distal stem diameters per tree) were taken within each stratum by striking each branch five times with a one-meter stick allowing specimens to fall onto a $1 \mathrm{~m} \times 1 \mathrm{~m}$ cloth. Branch clippings, consisting of four (24 cm with $1 \mathrm{~cm}$ proximal stem diameter) branches were taken within each stratum. Handpicking specimens involved visual observations, conducted on each tree for $5 \mathrm{~min}$ per stratum on each tree, and was standardized over an area of $3 \mathrm{~m} \times 3 \mathrm{~m}$ with all observed mycetophilids collected. Trunk vacuuming was standardized over an area of $61 \mathrm{~cm} \times 30 \mathrm{~cm}$ on the trunk.

\subsection{Preserving and Identifying Specimens}

Specimens collected from direct sampling were placed into pre-labeled (date, tree number, cardinal direction, stratum, and collecting method) vials (6 dram) containing 75\% alcohol. All specimens collected were sorted and identified to family, genus, and species. For each taxon, insect specimens were sorted into vials (4 dram) filled with $75 \%$ alcohol and labeled. Specimens were identified using mycetophilid keys [1,25-28]. Voucher specimens were organized into Cornell drawers and incorporated into the University of Tennessee's insect museum.

\subsection{Data Analysis}

Data (collection date, collection method, tree number, block number, order, family, genus, species, author, number of specimens, and guild) were entered into an Excel ${ }^{\circledR}$ spreadsheet. Samples were 
pooled across all collection methods and dates for each stratum for abundance (number of specimens) and species richness (number of species) analysis. Shapiro-Wilks W test for normality and Levene's test of homogeneity of variances were used to verify that abundance and species richness data conformed to the assumptions of analysis of variance (ANOVA). The assumptions of normality and homogeneity of variances were met. Abundance and species richness over all strata were analyzed using repeated measures ANOVA and means were separated using LSD procedures in SAS [29]. The potential number of mycetophilid species for each stratum was estimated using the Chaol estimator using the software EstimateS 5.0.1 [30]. The Chaol estimator was selected because, when compared with other estimators, it trends toward intermediate species richness estimates. Differences in species composition among strata were determined using analysis of similarity (ANOSIM) on Bray-Curtis distances constructed in a resemblance matrix using PRIMER version 6 software [31]. Samples were pooled across collection method for each stratum and collection date. Differences in composition were illustrated using two-dimensional non-metric multidimensional scaling (NMDS). Using the stress levels obtained by fitting the dissimilarities to the Bray-Curtis distance, a two-dimensional NMDS was chosen as the best representation (stress $=0.01$ ) of the dissimilarities of community composition among strata. Since these tests are based on the assumptions that sampling has been reasonably completed, observed species accumulation curves were plotted against Chao1, Chao2, Jackknife 1, Michaelis-Menten, ACE, and ICE estimated accumulation curves. In all cases, the observed curve was identical in shape, culminating in a plateau, indicating reasonably completed sampling.

To assess random and non-random co-occurrence patterns, a null model was established that species co-occur within a stratum randomly. Data were organized into a presence-absence matrix and imported into ECOSIM 7.0. A fixed-fixed null model algorithm was used to retain totals in the simulation with 5000 iterations. A fixed-fixed model algorithm was chosen so differences in the frequency of occurrence of each mycetophilid species (row sums) and differences in the number of mycetophilid species per tree stratum were preserved. Additionally, this algorithm is less prone to type I errors and has good power for detecting non-randomness. The Stone and Roberts' [32] C-score index was used to quantify co-occurrence because of its minimal chance of Type I and Type II errors relative to other indices [33]. The C-score index is a measure of the proportion of species pairs that do not co-occur among a group of communities [34].

\section{Results}

\subsection{Species Diversity, Abundance, and Richness}

During this study, 990 adult mycetophilid specimens were collected and identified, representing 14 genera and 24 species (Table 1). Mycetophilid abundance and species richness means were significantly affected by stratum effects $(F=118.04$; df $=3 ; p<0.05)$. Of the 990 specimens collected, 480 specimens were obtained from the lower stratum representing 10 genera and 13 species. In the middle stratum, 377 specimens were collected, representing eight genera and 11 species, while only 133 specimens were collected in the upper stratum representing five genera and five species. Abundance was significantly different (LSD test; $p<0.05$ ) among strata (Figure 1). Abundance was 
significantly higher (LSD test; $p<0.05$ ) in the lower stratum compared to the middle and upper strata. The middle stratum contained significantly higher (LSD test; $p<0.05$ ) number of specimens than the upper stratum. Species richness was significantly higher (LSD test; $p<0.05$ ) in the lower canopy stratum compared to the middle and upper strata (Figure 2). Species richness was higher in the middle compared to the upper stratum (LSD test; $p<0.05$ ). Chao1 species richness estimates (Figure 2) for each stratum infer that the lower stratum had the highest mean estimate of species richness $(n=14)$ followed by the middle stratum $(n=13)$ and the upper stratum $(n=7)$, which coincides with the observed mean species richness. Overall abundance was even, there were no recorded singletons (species in which only one specimen was recorded) or doubletons (species in which only two specimens were recorded). This may be due to the structural complexity of eastern hemlocks which may lead to fine portioning of available space as a result the pattern of abundance appears more even.

Table 1. Vertically sampled mycetophilid species associated with eastern hemlock in the southern Appalachians and corresponding collection methods.

\begin{tabular}{|c|c|c|c|c|}
\hline Genus & Species & Author & $\begin{array}{l}\text { Collecting } \\
\text { Method * }\end{array}$ & $\begin{array}{l}\text { Number of } \\
\text { Specimens }\end{array}$ \\
\hline Boletina & tricincta & Loew & $\mathrm{B}, \mathrm{BC}, \mathrm{H}$ & 23 \\
\hline Bolitophila & cinerea & Meigen & $\mathrm{B}, \mathrm{BC}, \mathrm{T}$ & 24 \\
\hline Bolitophila & disjuncta & Loew & $\mathrm{B}, \mathrm{T}$ & 32 \\
\hline Bolitophila & hybrida & Meigen & $\mathrm{B}, \mathrm{BC}, \mathrm{H}$ & 17 \\
\hline Docosia & dichroa & Loew & $\mathrm{B}, \mathrm{T}$ & 33 \\
\hline Dynatosoma & fulvidum & Coquillett & $\mathrm{B}, \mathrm{H}, \mathrm{T}$ & 113 \\
\hline Dynatosoma & placidum & Johannsen & $\mathrm{B}, \mathrm{BC}, \mathrm{H}$ & 45 \\
\hline Lasiosoma & fasciata & Say & $\mathrm{B}, \mathrm{H}, \mathrm{T}$ & 19 \\
\hline Leia & bivittata & Say & $\mathrm{B}, \mathrm{BC}, \mathrm{T}$ & 25 \\
\hline Leia & decora & Loew & $\mathrm{B}, \mathrm{BC}, \mathrm{H}, \mathrm{T}$ & 175 \\
\hline Leptomorphus & subcaerulea & (Coquillett) & $\mathrm{B}, \mathrm{BC}, \mathrm{H}$ & 16 \\
\hline Mycetophila & fallax & Loew & $\mathrm{H}, \mathrm{T}$ & 18 \\
\hline Mycetophila & quatuornotata & Loew & $\mathrm{BC}, \mathrm{T}$ & 13 \\
\hline Mycetophila & punctata & Meigen & $\mathrm{BC}, \mathrm{T}$ & 46 \\
\hline Mycomya & vulgaris & Garrett & $\mathrm{B}, \mathrm{H}, \mathrm{T}$ & 19 \\
\hline Orfelia & genualis & (Johannsen) & $\mathrm{BC}, \mathrm{T}$ & 39 \\
\hline Phronia & bicolor & Dziedzicki & $\mathrm{H}, \mathrm{T}$ & 45 \\
\hline Phronia & braueri & Dziedzicki & $\mathrm{BC}, \mathrm{H}, \mathrm{T}$ & 16 \\
\hline Phronia & cinerascens & Winnertz & $\mathrm{B}, \mathrm{H}, \mathrm{T}$ & 28 \\
\hline Phronia & conformis & (Walker) & $\mathrm{B}, \mathrm{BC}, \mathrm{H}, \mathrm{T}$ & 44 \\
\hline Saigusaia & cincta & (Johannsen) & $\mathrm{B}, \mathrm{BC}, \mathrm{H}, \mathrm{T}$ & 52 \\
\hline Synapha & tibialis & (Coquillett) & $\mathrm{B}, \mathrm{BC}, \mathrm{H}, \mathrm{T}$ & 118 \\
\hline Zygomyia & ornata & Loew & $\mathrm{B}, \mathrm{H}, \mathrm{T}$ & 19 \\
\hline Zygomyia & ignobillis & Loew & $\mathrm{BC}, \mathrm{H}, \mathrm{T}$ & 11 \\
\hline
\end{tabular}

* B: Beat Sheet; BC: Branch Clipping; H: Handpicking; T: Trunk Vacuuming. 
Figure 1. Mean abundance (mean number of individuals \pm SE) for each stratum. Means $(n=6)$ with different letters are significantly different (LSD test; $p<0.05)$.

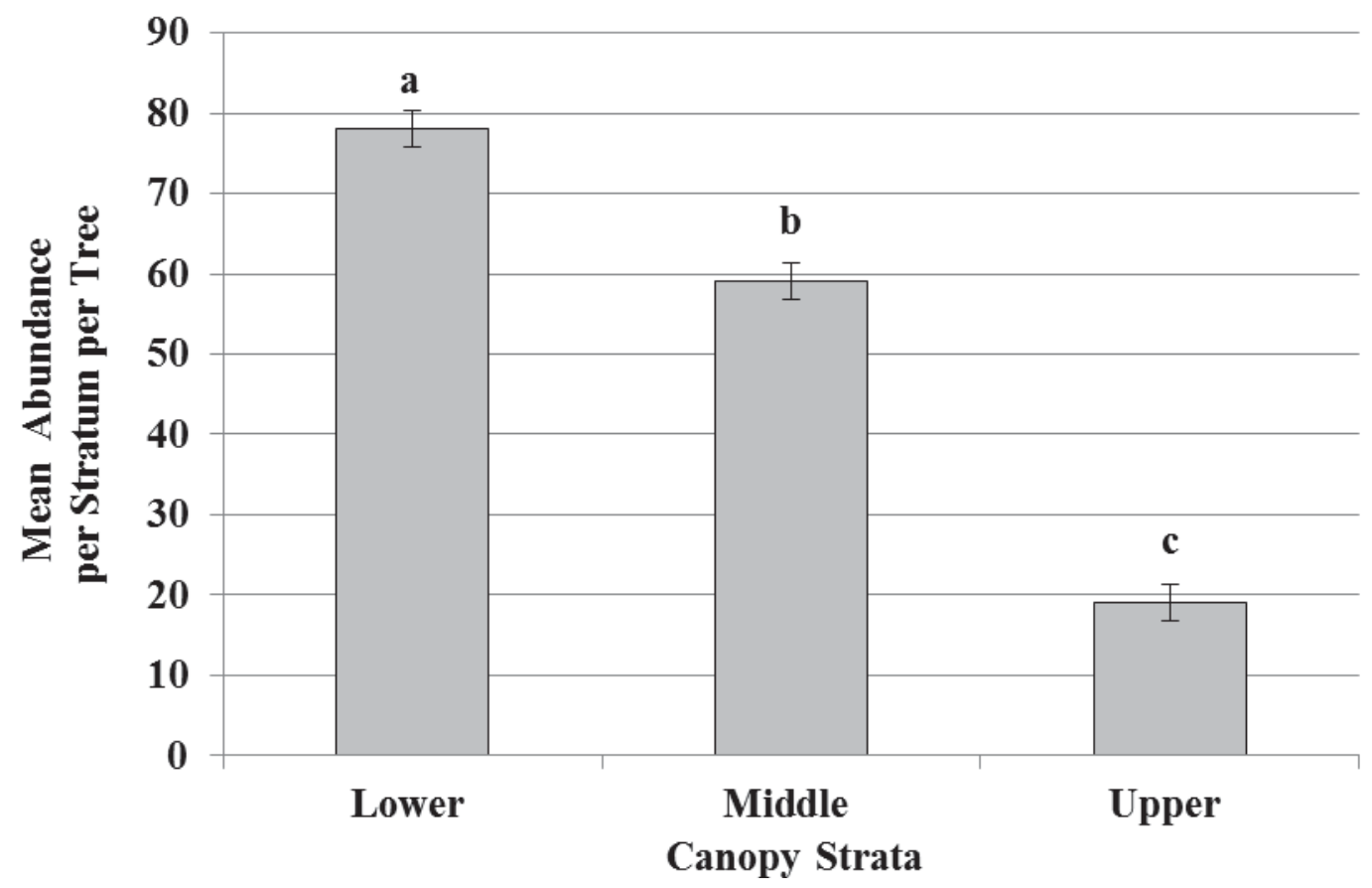

Figure 2. Observed mean species richness (mean number of species $\pm \mathrm{SE}$ ) for each stratum and Chao1 mean $( \pm 95 \% \mathrm{CL})$ species richness estimate. Means $(n=6)$ with different letters are significantly different (LSD test; $p<0.05$ ).

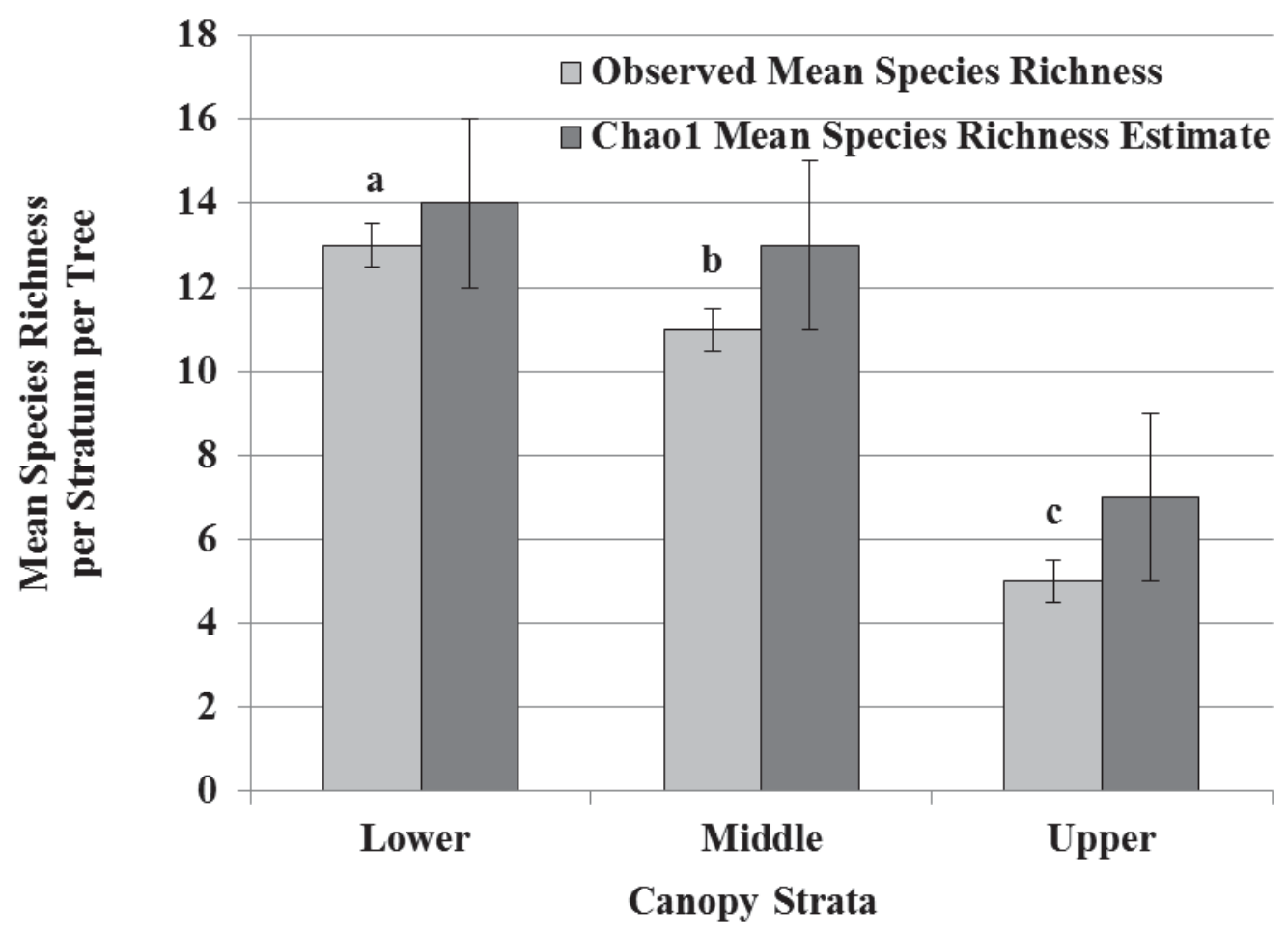




\subsection{Species Composition, Vertical Stratification, and Co-Occurrence Pattern}

Mycetophilid species composition among strata exhibited a high degree of dissimilarity (ANOSIM $R=0.985, n=18, p<0.0001$ ) (Figure 3) resulting in unique identifiable assemblages within each stratum of the tree. The upper stratum had four unique species (species only found in a respective stratum): Bolitophila cinerea Meigen, Docosia dichroa Loew, Dynatosoma placidum Johannsen, and Mycetophila quatuornotata Loew. Phronia cinerascens Winnertz was the only species found in both upper and middle strata. The middle stratum had six unique species: Bolitophila disjuncta Loew, Dynatosoma fulvidum Coquillett, Lasiosoma fasciata Say, Orfelia genualis (Johannsen), Saigusaia cincta (Johannsen), and Zygomyia ignobillis Loew. Leptomorphus subcaerulea (Coquillett), Phronia bicolor Dziedzicki, Phronia conformis (Walker), and Synapha tibialis (Coquillett) were found in both the middle and lower strata. The lower stratum had nine unique species: Boletina tricincta Loew, Bolitophila hybrida Meigen, Leia bivittata Say, Leia decora Loew, Mycetophila fallax Loew, Mycetophila punctata Meigen, Mycomya vulgaris Garrett, Phronia braueri Dziedzicki, and Zygomyia ornata Loew. No species were collected from all three strata.

Figure 3. Non-metric multidimensional scaling (NMDS) ordination of mycetophilid communities on six eastern hemlock trees sampled three times based on abundance and Bray-Curtis similarities. Each individual point represents a stratum within a host tree sampled at one sampling time. Distance between points represents the degree of dissimilarity in species composition, i.e., the further the distance, the more dissimilar the species composition.

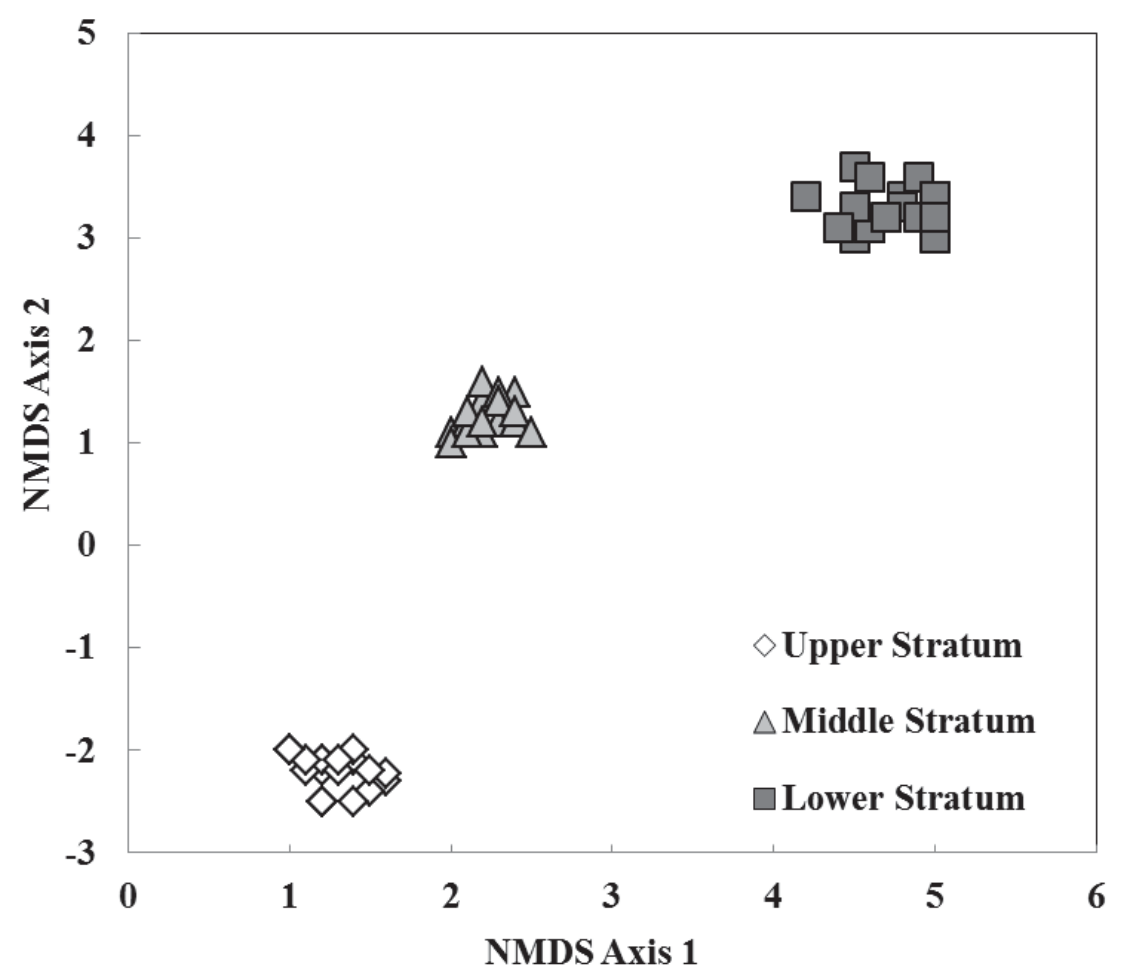

The mean observed C-score $(\mathrm{C}$-score observed $=376.38)$ was significantly greater $\left(p_{\text {obs }>\text { exp }}=0.0001\right)$ than the mean of the randomly simulated index $(\mathrm{C}$-score expected $=329.13)$. These higher observed 
C-scores indicate less co-occurrence than expected by chance, thus, suggesting a non-random competitively structured community [34]. The probability that the mean observed C-score would be significantly lower than the mean of the randomly simulated index was not significant $\left(p_{\text {obs }<\exp }=0.999\right)$.

\section{Discussion}

In this study, 24 species of mycetophilids were identified within eastern hemlock in the southern Appalachians. The biodiversity of this taxon is important to document to better understand the biology and ecology of those species associated with and found among eastern hemlock. While the type of association mycetophilids have with eastern hemlock is not well understood and may well be transient, they constitute a vital component of the food web found in this system. This type of information is fundamental to developing conservation-based management strategies against hemlock woolly adelgid. For example, using tree injections of imidacloprid, a systemic insecticide used to control hemlock woolly adelgid, instead of soil drench or soil injection applications, could reduce the impact on mycetophilids and other non-target species that pupate below the soil line around the tree. The lower stratum had the highest diversity of species and mycetophilid abundance, followed by the middle and upper strata, respectively. A similar trend was documented with species of Psocoptera on eastern hemlock in the southern Appalachians [11]. This pattern of diversity may indicate a broader range of habitats and resources available in the lower stratum compared with those in the middle and upper strata not only for mycetophilids, but species of other taxa as well. For example, a higher moisture availability exists within the lower stratum. Ulyshen [35] noted that changes in the availability of moisture from damp forest floors to the top of the forest canopy can be an important component in governing fungal communities. Lower light levels found in the bottom canopy are conducive to development of fungal species with high shade requirements [35] and may result in more diverse fungal communities that contribute to the development of arthropod communities highly dependent on these fungal species. An increased amount of dead wood, woody debris, and bark surface area are associated within the bottom branches of the canopy which contribute to an increased range of habitats and resources available to mycetophilids. Increased transparency of the canopy due to hemlock woolly adelgid infestations can increase the light penetration to the forest floor, and may alter associated arthropod communities by changing the moisture gradients and light penetration, and increasing the amount of woody debris. In this study, trees with similar tree characteristics were selected; however, it is important to note that changes in tree height, canopy transparency, canopy density, crown class, diameter at breast height, crown condition, and percent of tree infested with hemlock woolly adelgid may contribute to altering both fungal and arthropod communities. Further research is needed to examine the biodiversity of fungal communities associated with eastern hemlock and the direct relationship between habitat association and resource use and the mycetophilids documented in this study.

The non-random co-occurrence patterns found in this study may infer competitive interactions; however, it is important to note that non-random structure can also be attributed to other mechanisms, such as species-environment relationships, non-random spatial processes, non-overlapping habitats or niches, and historical effects [33,36,37]. Non-random spatial processes within the canopy of eastern 
hemlock may dictate resource distribution influencing how species distribute throughout the canopy. Additionally, only the adult life stage was collected; it is possible that these unique assemblages present in each stratum may be confined to this particular life stage, or maybe the result of migratory behavior. Additional research is needed to further investigate the possible mechanisms for vertical stratification throughout all life stages.

\section{Conclusions}

This study is the first assessment of the mycetophilid community found within the canopy of eastern hemlock in the southern Appalachians focused on entire canopy sampling. Eastern hemlocks are an attractive habitat to mycetophilids providing them with a favorable temperature and humidity regime, available food resources, and possibly a degree of protection from their natural enemies. While the direct association of mycetophilid species in eastern hemlock is not well understood, they constitute an integral component of the food web and changes in their community structure resulting from infestation by the hemlock woolly adelgid and subsequent management practices, such as chemical treatments, are unknown and represent an area in need of further research.

\section{Acknowledgments}

We thank D. Paulsen, A. Hakeem, N. Reynolds, T. Conatser, and G. Wiggins (Department of Entomology and Plant Pathology, University of Tennessee, Knoxville, TN, USA) for assistance with field experiments, personnel at the Tellico Plains Ranger Station (Cherokee National Forest, Monroe County, TN, USA, for their assistance in setting up the test sites, and the USDA Forest Service, Forest Health Protection for financial support of this project.

\section{Conflict of Interest}

The authors declare no conflict of interest.

\section{References}

1. Vockeroth, J.R. Mycetophilidae. In Manual of Nearctic Diptera Volume 1; Research Branch Agriculture Canada Monograph No. 27; McAlpine, J.F., Peterson, B.V., Shewell, G.E., Teskey, H.J., Vockeroth, J.R., Wood, D.M., Eds.; Canadian Government Publishing Centre: Quebec, Canada, 1981; pp. 223-246.

2. Triplehorn, C.A.; Johnson, N.F. Introduction to the Study of Insects, 7th ed.; Thomson Brooks/Cole Press: Belmont, CA, USA, 2004; p. 718.

3. Didham, R.K. Dipteran Tree-Crown Assemblages in a Diverse Southern Temperate Rainforest. In Canopy Arthropods; Stork, N.E., Adis, J., Didham, R.K., Eds.; Chapma and Hall: London, UK, 1997; pp. 551-561.

4. Godman, R.M.; Lancaster, K. Tsuga canadensis (L.) Carr. Eastern Hemlock. In Silvics of North America: Volume 1, Conifers, Agricultural Handbook 654; Burns, R.M., Honkala, B.H., Eds.; U.S. Department of Agriculture, Forest Service: Washington, DC, USA, 1990; pp. 604-612. 
5. Ward, J.S.; Montgomery, M.E.; Cheah, C.A.S.-J.; Onken, B.P.; Cowles, R.S. Eastern Hemlock Forests: Guidelines to Minimize the Impacts of Hemlock Woolly Adelgid; U.S. Department of Agriculture, Forest Service: Morgantown, WV, USA, 2004; p. 27.

6. Erwin, T.L. Measuring Arthropod Biodiversity in the Tropical Rainforest Canopy. In Forest Canopies; Lowman, M.D., Nadkarni, N.M., Eds.; Academic Press: San Diego, CA, USA, 1995; pp. 109-127.

7. Winchester, N.N. Canopy Arthropods of Coastal Sitka Spruce Trees on Vancouver Island, British Columbia, Canada. In Canopy Arthropods; Stork, N.E., Adis, J., Didham, R.K., Eds.; Chapman and Hall: London, UK, 1997; pp. 151-168.

8. Buck, S.; Lambdin, P.; Paulsen, D.; Grant, J.; Saxton, A. Checklist of insect species associated with eastern hemlock in the Great Smoky Mountains National Park and environs. Tennessee Acad. Sci. 2005, 80, 1-10.

9. Dilling, C.I.; Lambdin, P.L.; Grant, J.F.; Buck, S.L. Insect guild structure associated with eastern hemlock in the southern Appalachians. Environ. Entomol. 2007, 36, 1408-1414.

10. Dilling, C.I.; Lambdin, P.L.; Grant, J.F.; Rhea, J.R. Community response of non-target phytophagous and transient insects associated with eastern hemlock, Tsuga canadensis (L.) Carrière, to imidacloprid and horticultural oil treatments. Environ. Entomol. 2009, 38, 53-66.

11. Coots, C.I.; Lambdin, P.L.; Grant, J.F.; Rhea, J.R.; Mockford, E.L. Vertical stratification and co-occurrence patterns of the Psocoptera community associated with eastern hemlock, Tsuga canadensis (L.) Carrière, in the Southern Appalachians. Forests 2011, 3, 127-136.

12. Wallace, M.S.; Hain, F.P. Field surveys and evaluation of native and established predators of the hemlock woolly adelgid (Homoptera: Adelgidae) in the southeastern United States. Environ. Entomol. 2000, 29, 638-644.

13. Daubenmire, R.F. Factors favoring the persistence of a relic association of eastern hemlock in Indiana. Butler Univ. Bot. Stud. 1931, 2, 29-32.

14. Friesner, R.C.; Potzger, J.E. Studies in forest ecology, II. The ecological significance of Tsuga candensis in Indiana. Butler Univ. Bot. Stud. 1932, 2, 133-149.

15. Friesner, R.C.; Potzger, J.E. Climax conditions and ecological status of Pinus strobus, Taxus canadensis, and Tsuga canadensis in the Pine Hills region of Indiana. Butler Univ. Bot. Stud. 1934, 3, 65-83.

16. Friesner, R.C.; Potzger, J.E. Soil moisture and the nature of the Tsuga and Tsuga-Pinus forest association in Indiana. Butler Univ. Bot. Stud. 1936, 3, 207-209.

17. Friesner, R.C.; Potzger, J.E. Survival of hemlock seedlings in a relic colony under forest conditions. Butler Univ. Bot. Stud. 1944, 6, 102-115.

18. Hough, A.F. Frost pockets and other microclimates in forests of the northern Allegheny Plateau. Ecology 1945, 26, 230-250.

19. Moore, B.; Richards, H.M.; Gleason, H.A.; Stout, A.B. Hemlock and its environment. Field records. New York Bot. Gard. Bull. 1924, 12, 325-350.

20. Oosting, H.J.; Hess, D.W. Microclimate and relict stand of Tsuga canadensis in the lower Peidmont of North Carolina. Ecology 1956, 37, 28-39.

21. Shreve, F. Soil temperature in redwood and hemlock forests. 1927. Bull. Torrey Bot. Club 1927, $54,649-656$. 
22. Basset, Y.; Hammond, P.M.; Barrios, H.; Holloways, J.D.; Miller, S.E. Vertical Stratification of Arthropod Assemblages. In Arthropods of Tropical Forests; Bassett, Y., Novotny, V., Miller, S.E., Kitching, R.L., Eds.; Cambridge University Press: Cambridge, UK, 2003; pp. 17-27.

23. Hakeem, A. Effect of Imidacloprid on the Predatory Arthropod Guild on Eastern Hemlock, Tsuga canadensis (L.) Carrière, in the Southern Appalachians. Master's Thesis, The University of Tennessee, Knoxville, TN, USA, 2008; p. 78.

24. Eyre, F. Forest Cover Types of the United States and Canada; Society of American Foresters: Washington, DC, USA, 1980; p. 156.

25. Johannsen, O.A. The fungus gnats of North America. The Mycetophilidae of North America. Part I. Bull. ME Agric. Exp. Stn. 1909, 172, 209-276.

26. Johannsen, O.A. The fungus gnats of North America. The Mycetophilidae of North America. Part II. Bull. Me Agric. Exp. Stn. 1910, 180, 125-192.

27. Johannsen, O.A. The fungus gnats of North America. The Mycetophilidae of North America. Part III. Bull. ME Agric. Exp. Stn. 1911, 196, 249-328.

28. Johannsen, O.A. The fungus gnats of North America. The Mycetophilidae of North America. Part IV. Bull. ME Agric. Exp. Stn. 1912, 200, 57-146.

29. SAS Institute. SAS User's Guide: Statistics, Version 9.1; SAS Institute: Cary, NC, USA, 2005; p. 201.

30. Colwell, R.K. EstimateS: Statistical Estimation of Species Richness and Shared Species from Samples, Version 5; User's Guide and Application. Available online: http://viceroy.eeb. uconn.edu/estimates (accessed on 31 May 2012).

31. Clarke, K.R.; Gorley, R.N. PRIMER Version 6: User Manual/Tutorial; PRIMER-E: Plymouth, UK, 2006; p. 156.

32. Stone, L.; Roberts, A. The checkerboard score and species distributions. Oecologia 1990, 85, 74-79.

33. Gotelli, N. Null model analysis of species co-occurrence patterns. Ecology 2000, 81, 2606-2621.

34. Gotelli, N.J.; Entsminger, G.L. Swap and fill algorithms in null model analysis: Rethinking the Knight's Tour. Oecologia 2001, 129, 281-291.

35. Ulyshen, M.D. Arthropod vertical stratification in temperate deciduous forests: Implications for conservation management. For. Ecol. Manag. 2011, 261, 1479-1489.

36. Gotelli, N.J.; McGill, B.J. Null versus neutral models: What's the difference? Ecography 2006, 29, 793-800.

37. Gotelli, N.J.; McCabe, D.J. Species co-occurrence: A meta-analysis of J. M. Diamond's assembly rules. Ecology 2002, 83, 2091-2096.

(C) 2012 by the authors; licensee MDPI, Basel, Switzerland. This article is an open access article distributed under the terms and conditions of the Creative Commons Attribution license (http://creativecommons.org/licenses/by/3.0/). 